\title{
Coronary atherosclerosis in medico-legal autopsy cases
}

\author{
Prasad VN 1 , Jha $\mathrm{A}^{2}$, Adhikari $\mathrm{RC}^{2}$, Sayami G${ }^{2}$, Shrestha $\mathrm{PK}^{3}$, Shrestha $\mathrm{HG}^{2}$ \\ ${ }^{I}$ Department of Pathology, National Medical College, Birgunj, Nepal. \\ ${ }^{2}$ Department of Pathology, Institute of Medicine, Maharajgunj, Kathmandu, Nepal. \\ ${ }^{3}$ Department of Forensic Medicine, Institute of Medicine, Maharajgunj, Kathmandu.
}

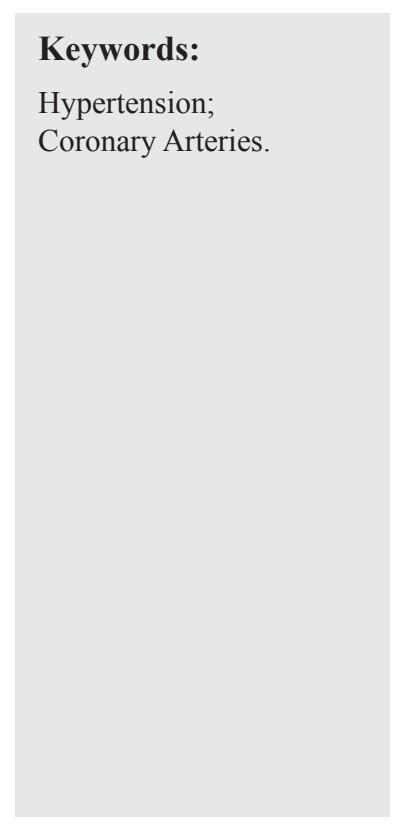

\begin{abstract}
Background: Coronary atherosclerosis is the major cause of death worldwide. Lifestyle and habits are the major contributory factor in the development of coronary atherosclerosis.

Materials and Methods: This is an autopsy-based study in which 45 autopsy cases were randomly selected for study. Proximal one third of all three epicardial coronary arteries (LAD, LCX and RCA) were dissected out for study and serial sections were made and stained with H\&E method and under the light microscope. Atherosclerosis was graded according to American heart association classification. The risk factors (cigarette smoking, hypertension, diabetes, alcohol consumption, age, sex) were also correlated with the grade of atherosclerosis.
\end{abstract}

Results: Seventy-Eight percent of American Heart Association classification grade V lesions were seen in $>70 \mathrm{yrs}$ of age. Almost all cases of $>70 \mathrm{yrs}$ of age had American Heart Association classification grade $>$ IV lesions. Out of all grade IV lesions, $88.9 \%$ was seen in male while only $11.1 \%$ in female. Similarly out of all grade V lesions, $77.8 \%$ was seen in male while $22.2 \%$ in female. LAD showed maximum involvement by higher grade lesion, followed by LCX and RCA. American Heart Association classification grade > IV in LAD, LCX and RCA was seen in 25(55.6\%), 5 (11.1\%), and 3(6.7\%) cases respectively.

Conclusion: Higher grade lesion occurs in advancing age. Various cardiovascular risk factors were significantly associated with higher grade of lesions. The multiple risk factors had a synergistic effect on the progression of coronary atherosclerosis.

\section{INTRODUCTION}

Coronary artery disease remains globally the leading cause of death and long term morbidity. ${ }^{1}$ Lifestyles and dietary habits are the major contributory factors for the changing trends. ${ }^{1,2}$ According to WHO bulletin 2000; 5.6\% people living in mountains, $1.5 \%$ in hills and $5 \%$ of people in Terai

\footnotetext{
Correspondence:

Dr Abhimanyu Jha, MD

Associate Professor, Department of Pathology

Institute of Medicine, Tribhuvan University, Teaching Hospital,

Maharajgunj, Kathmandu. Email: jhaabhimanyu@yahoo.com

Phone: 977-9851011684
}

region are suffering from cardiovascular disease in Nepal. ${ }^{3}$ Different studies have shown the co-existence of multiple risk factors confers a magnified risk which is multiplicative rather than additive. ${ }^{4,5} \mathrm{~A}$ smoker with modest elevation of cholesterol and blood pressure is at greater risk of coronary death than a non smoker with severe hypertension or marked hypercholesterolemia. This study is an autopsy-based study showing the prevalence of coronary atherosclerosis and its histological grading according to American Heart Association classification (AHA) and its association with various modifiable or non modifiable risk factors like age, 
sex, diabetes mellitus, hypertension, smoking and alcohol intake. The progression of atherosclerotic lesion with increasing severity relate not only to the presence of and extent of cardiovascular (CV) risk factors but also to the persistence of risk factors over time. Epidemiologic studies have established that multiple risk factors increase the probability of events, since $\mathrm{CV}$ risk factors tend to reinforce each other in their influence in morbidity and mortality. ${ }^{6-9}$

\section{MATERIALS AND METHODS}

This was a cross-sectional study conducted at the department of Pathology and the department of Forensic medicine of Institute of Medicine, Tribhuvan University Teaching Hospital, Kathmandu. Forty five medicolegal autopsy cases, over 20 years of age were randomly selected. During autopsy procedure, the heart was taken out by the forensic pathologist and preserved in $10 \%$ formalin. In the histopathology laboratory, four serial sections from each of the three coronary arteries were taken and processed. Hematoxylin and Eosin (H\&E) staining was performed and coronary pathology was studied under light microscope. Grading of the coronary atherosclerosis was done according to AHA Classification into grade one to six.

\section{RESULTS}

The age distribution of 45 cases included in the study is shown in table 1 . The mean age was 52.5 years. For the purpose of clinical correlation the cases were divided into two groups of less then and more than 40 year. Majority of cases were in $>40$ yrs (33 cases). There were 31 male and 14 female with male to female ratio of 2.2:1.

AHA grade of atheromatous plaque in different age groups is shown in table 2 and fig. 1-5. Seventy eight percent of AHA grade $\mathrm{V}$ lesions were seen in $>70 \mathrm{yrs}$ of age. Almost all cases of $>70$ yrs of age had AHA grade $>$ IV lesions (Table 2).

Higher grade lesions were common in male than female. Out of all grade IV lesions, $88.9 \%$ was seen in male while only $11.1 \%$ in female. Similarly out of all grade V lesions, $77.8 \%$ was seen in male while $22.2 \%$ in female.

On anatomical basis, LAD showed maximum involvement by higher grade lesion, followed by LCX and RCA. AHA grade > IV in LAD, LCX and RCA was seen in $25(55.6 \%)$, $5(11.1 \%)$, and $3(6.7 \%)$ cases respectively (Table 3$)$.

Study also concluded significant association of cardiovascular risk factors with higher grade lesion in coronary arteries (Table 4). Among the risk factors, smoking and alcohol consumption were seen in large number of cases. $78.6 \%$ of smokers and $74.1 \%$ of alcoholics were associated with higher grades lesions (AHA>IV). Out of 25 cases with higher grade lesions, 23 (92\%) were associated with
Table 1: Age distribution of cases

\begin{tabular}{ccc}
\hline Age (years) & No. of cases & \% \\
\hline $20-29$ & 5 & 11.1 \\
\hline $30-39$ & 7 & 15.6 \\
\hline $40-49$ & 8 & 17.8 \\
\hline $50-59$ & 9 & 20 \\
\hline $60-69$ & 4 & 8.9 \\
\hline$>70$ & 12 & 26.7 \\
\hline Total & 45 & 100 \\
\hline
\end{tabular}

Table 2: Age wise Distribution of AHA Grade lesions

\begin{tabular}{cccc}
\hline Age(years) & $\begin{array}{c}\text { AHA Grade in Coronary } \\
\text { Arteries }\end{array}$ & Total \\
\hline & $<\mathrm{IV}$ & $>\mathrm{IV}$ \\
$20-29$ & 5 & 0 & 5 \\
$30-39$ & 5 & 2 & 2 \\
\hline $40-49$ & 4 & 4 & 8 \\
\hline $50-59$ & 3 & 6 & 9 \\
\hline $60-69$ & 1 & 3 & 4 \\
\hline$>-70$ & 0 & 12 & 12 \\
\hline Total & $\mathbf{1 8 ~ ( 4 0 \% )}$ & $\mathbf{2 7}(\mathbf{6 0} \%)$ & $\mathbf{4 5}$ \\
\hline
\end{tabular}

Table 3: Involvement of different Coronary Arteries

\begin{tabular}{cccc}
\hline AHA Grade & LAD & LCX & RCA \\
\hline AHA Grade $<$ IV & 20 & 40 & 42 \\
AHA Grade >-IV & 25 & 5 & 3 \\
Total number & $\mathbf{4 5}$ & $\mathbf{4 5}$ & $\mathbf{4 5}$ \\
\hline
\end{tabular}

Table 4: Association of Risk factors with Coronary Atherosclerosis

\begin{tabular}{lcccc}
\hline Risk factors & No. of cases & \multicolumn{2}{c}{ AHA Grade } & p value \\
\hline & & $<$ IV & $>$-IV & \\
Smoking & 28 & 6 & 22 & 0.001 \\
Alcohol consumption & 27 & 7 & 20 & 0.006 \\
Hypertension & 11 & 1 & 10 & 0.014 \\
Diabetes Mellitus & 4 & 1 & 3 & 0.625 \\
\hline
\end{tabular}

Table 5: Association of single and multiple Risk factors with Coronary Atherosclerosis

\begin{tabular}{cccc}
\hline $\begin{array}{c}\text { Number of } \\
\text { risk factors }\end{array}$ & \multicolumn{2}{c}{ AHA Grade } & Total \\
\hline & $<\mathrm{IV}$ & $>\mathrm{IV}$ & \\
Single & 5 & 2 & 7 \\
Multiple & 5 & 23 & 28 \\
\hline Total & $\mathbf{1 0}$ & $\mathbf{2 5}$ & $\mathbf{3 5}$ \\
\hline
\end{tabular}




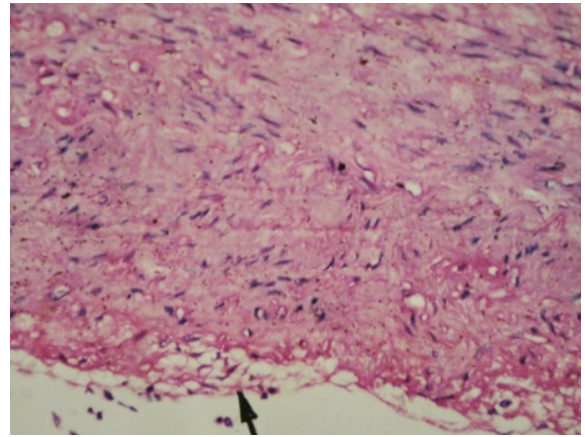

Figure 1: AHA grade I showing isolated foam cells in the intima of coronary artery $(H \& E$ stain X20).

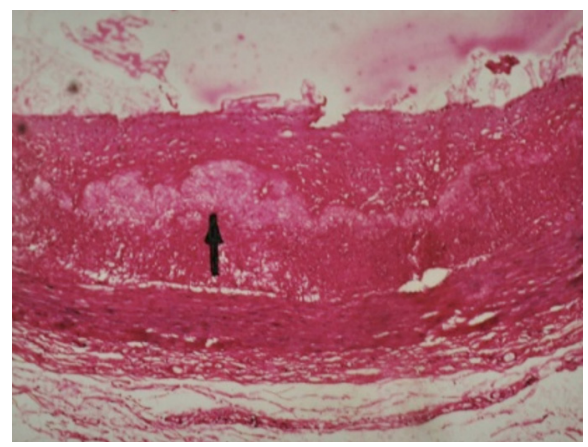

Figure 3: AHA grade III showing extra cellular pools of lipid as well as scattered foam cells in the intima (H\&E stain X20).

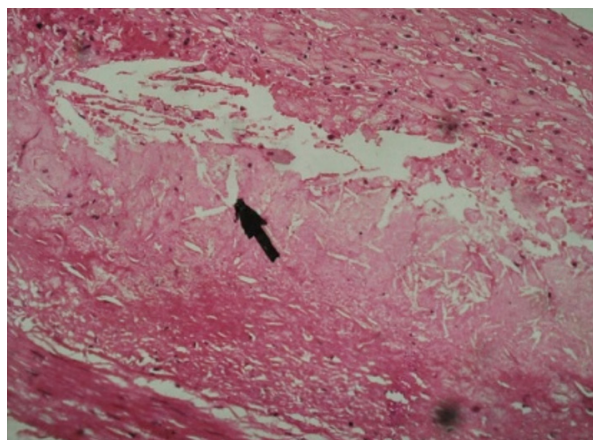

Figure 4b: AHA grade IV showing cholesterol cleft in the core of lipid (H\&E stain X20).

multiple risk factors while single risk factor was associated with only $2(8 \%)$ cases of same grade lesion (Table 5).

\section{DISCUSSION}

Atherosclerotic coronary disease is a leading cause of death and a major source of morbidity in developing countries. ${ }^{1}$ Autopsy study has demonstrated high prevalence of coronary atherosclerosis in advancing age and it is directly associated with the cardiovascular risk factors. CAD and its complication like arrhythmia, angina pectoris and

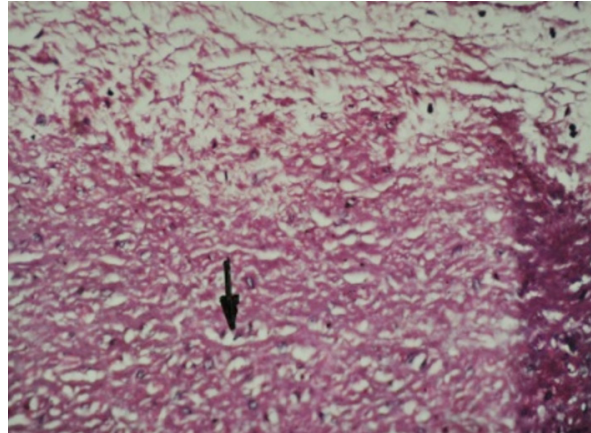

Figure 2: AHA grade II showing increase number of foam cells in the intima along with variable intimal thickening (H\&E stain X20).

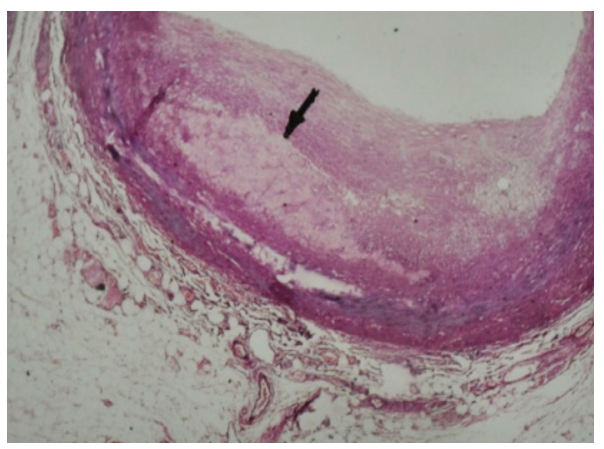

Figure 4a: AHA grade IV showing well defined core of extracellular lipids plus numerous scattered foam cells in the intima with intimal thickening. The media of the artery is thinned under the advanced plaque (H\&E stain X10).

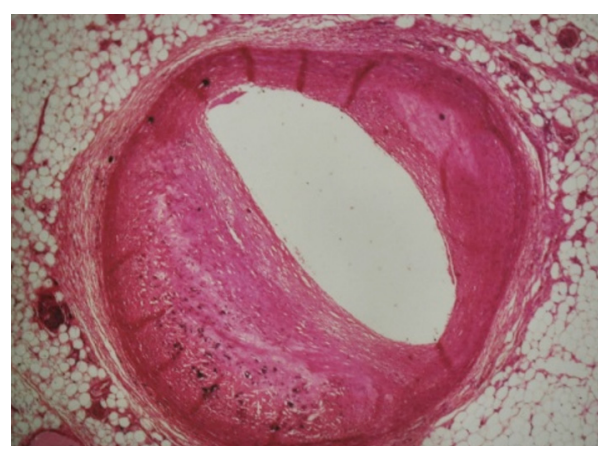

Figure 5a: AHA grade Vlesion showing core of lipids with calcification (H\&E stain X10).

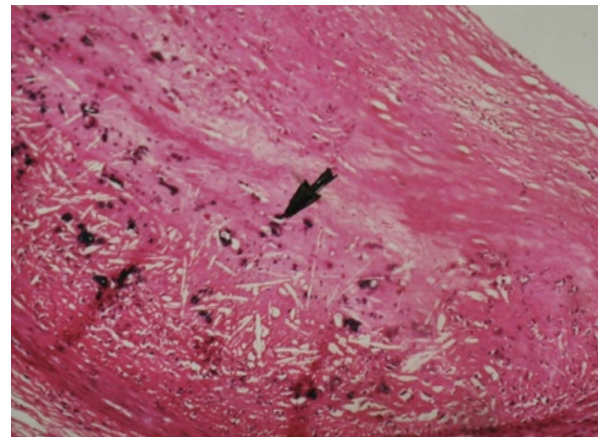

Figure 5b: AHA grade V showing lipid core with calcification and reactive fibrous cap on luminal surface of coronary artery (H\&E stain X20). 
myocardial infarction are leading cause of death in the United States. The lifetime risk of developing CAD after age 40 years is $49 \%$ for males and $32 \%$ for females. ${ }^{10}$ The present autopsy based study provides an evidence of atherosclerosis histopathologically in asymptomatic individuals with no evidence of clinical CAD.

In present study, all the three epicardial coronary arteries were examined microscopically. High grade lesions $(\mathrm{AHA}>=\mathrm{IV})$ were located in LAD (55.6\%), LCX (11.1\%) and RCA $(6.7 \%)$ but in another study done by E.MuratTuzcu et al., (2001), showed higher prevalence of atherosclerosis in LAD, lower prevalence within LCX and intermediate in RCA. ${ }^{11}$

In this study, $100 \%$ cases above 70 years age group showed advanced lesions(AHA $>=\mathrm{IV})$ and middle aged cases showed both types of lesions, while younger age group showed only lower grade lesions (AHA $<$ IV).

The results obtained by Mathur K.S. et al. in 1998, indicates the presence of coronary atherosclerosis with advancing age along with steep rise after the fourth decade and it continue to increase through the eight decade. ${ }^{12}$ These findings were also consistent with the present study. However the study done by Ackermanet $\mathrm{al}^{13}$ and White et $\mathrm{al}^{14}$ observed a terminal decline in the incidence of coronary atherosclerosis.

Present study also showed strong association of coronary atherosclerosis with various cardiovascular risk factors, like diabetes mellitus, smoking, hypertension and alcohol consumption. Furthermore, higher grade of lesions were associated with the coexistence of multiple risk factors. Findings similar to the present study was also shown by Gerald S. Berenson, Sathanur R. Srinivasan and William P. Newman, in 1998. ${ }^{15}$ These findings support the concept that multiple risk factors have a synergistic effect on the development of coronary atherosclerosis.

In this study, cigarette smoking and hypertension was associated with greater prevalence of AHA grade IV or $\mathrm{V}$ lesions. Similar association was also noted in the study performed by Auerbach et al. ${ }^{16}$ In this study, smoker tended to have greater intimal thickness due to increased density of fibrosis than nonsmoker. Cigarette smoking is a wellestablished risk factor in men and is thought to account for the relatively recent increase in the incidence and severity of atherosclerosis in women. Smoking one or more packs of cigarettes per day for several years increases the death rate from IHD by upto $200 \% .{ }^{17}$

In this study, out of 11 hypertensive, 10 (90.9\%) was associated with $>$ grade IV lesion. Hypertension is a major risk factor for atherosclerosis at all ages. Men between ages 45 and 62, whose blood pressure exceeds 169/90 $\mathrm{mm} \mathrm{Hg}$, have fivefold greater risk of IHD than those with blood pressure of 140/90 or lower. Similar correlation has been shown by Gerald S. Berenson et al. ${ }^{15}$ The extent of atherosclerotic lesion correlated positively and significantly with hypertension. Fibrous plaques in coronary arteries were more common in hypertensive than non-hypertensive. In hypertensive, there was less proliferation of foam cells, as seen in case of smokers.

In this study, out of 27 alcoholic, 20(74.1\%) was associated with higher grade lesion. Similar study performed by Klatsky Al et al showed the significant correlation of IHD with high doses of alcohol. ${ }^{18}$

Out of 4 diabetic cases in this study, $3(75 \%)$ had highgrade of coronary atherosclerosis. Similar populationbased autopsy study by Tauqir Y Garaya et al, diabetes was associated with higher prevalence of atherosclerosis. Among diabetic decedents without clinical CAD, almost three-fourths had high grade coronary atherosclerosis and more than half had multi-vessel disease. Non- diabetic women had less atherosclerosis than men, but this female advantage was lost with diabetes. ${ }^{19}$

D Prabhakaran et al from AIIMS, New Delhi, concluded that conventional risk factors remain at least as important in determining the risk of CAD in Indians as they are in other populations. In addition to these traditional risk factors, it is clear that there are other known and unknown factors which increase the predilection of Indians to develop premature and severe CAD. ${ }^{20}$ The most important set of conditions, which have been unequivocally associated with and are more prevalent among Indians with $\mathrm{CAD}$, are those constituting the syndrome of insulin resistance. Elevated levels of Lp(a) are seen in Indians irrespective of whether they reside in India or are immigrants to another country, suggesting a genetic predisposition and unhealthy lifestyle changes best explains the increased vulnerability of Indians to $\mathrm{CAD} .{ }^{21}$

As the history of risk factors association was provided by deceased party, it lacks detailed information especially regarding the quantity of alcohol and cigarette, thus the exact correlation was a matter of study limitation. For the discussion purposes, all the cases were divided into 2 age groups based on the vulnerability to develop coronary atherosclerosis. Thus the more vulnerable group included cases $\geq 40$ years of age, showed high prevalence of advanced lesion including calcification and less vulnerable group included cases $<40$ years of age, showed low grade of lesion in coronary arteries.

\section{CONCLUSION}

Coronary atherosclerosis begins at a younger age as a fatty streak lesion and progress to advanced lesion with increasing age. Out of 33 vulnerable cases, 25(75.8\%) cases had high grade lesion. Females had lower prevalence of high grade lesion than males. Among the risk factors, smoking and 
alcohol consumption showed maximum association with high grade lesion. Association of multiple risk factors had a synergistic effect, producing high grade lesion compared to single risk factor.

\section{REFERENCES}

1. Epidemiology of Noncommunicable diseases. In: text book of preventive and social medicine. Edited by Gupta MC, Mahajan BK. Jaypee brothers, 2003.pp 315-9.

2. Park K, editor. Park text book of preventive and social medicine. 17th ed. Banarsidas Bhanot publishers; 2002.830pp.

3. Bulletin of the WHO. 2000;75:31-3.

4. Dawber TR; The Framingham Study: The Epidemiology of Atherosclerotic Disease. 1980 Harvard University Press Cambridge:14-29. Crossref

5. Multiple Risk Factor Intervention Trial Research Group.1982. JAMA,248:1465. Crossref

6. McGill HC Jr, McMahan CA, Malconn GT, et al, for the PDAY Research Group. Effects of serum lipoproteins and smoking on atherosclerosis in young men and women. ArteriosclerThrombVasc Biol.1997; 17:95-10. Crossref

7. McGill HC Jr, McMahan CA, Tracy RE, et al, for the Pathological Determinants of Atherosclerosis in Youth (PDAY) Research Group. Relation of a postmortem renal index of hypertension to atherosclerosis and coronary artery size in young men and women. ArteriosclerThrombVasc Biol. 1998;18:1108-1118. Crossref

8. McGill HC Jr, McMahan CA, Henderick EE, Malcom GT, Tracy RE, Strong JP. Origin of atherosclerosis in childhood and adolescence. Am J Clin Nutr 2000;72:1307-15. PMID:11063473.

9. Sorlie PD, Garcia-Palieri MR, Costas Jr R, Oalmann MC. The relation of antemortem factors to atherosclerosis at autopsy. Am J Pathol 1981;103:345-52.

10. Ross R. The pathogenesis of atherosclerosis-A perspective for the 1990s. Nature 1993,362:801-9. Crossref

11. Tuzcu EM, Kapadia SR, et al. High Prevalance of Coronary Atherosclerosis in Asymptomatic Teenagers and Young Adults. Circ 2001;103:2705. Crossref
12. Mathur K.S., Patney NL, Kumar V. Atherosclerosis in India- An autopsy study of the aorta and the coronary, cerebral, renal, and pulmonary arteries. Circulation. 1961:vol XXI. [available from circ. ahajournals.org/content/21/5/730.full.pdf]

13. Ackerman RF, Dry TJ, Edward JE.Relationship of various factors to the degree of coronary atherosclerosis in women. Circ 1950;1:1345. Crossref

14. White NK, Edward JE, Dry TJ.The relationship of the degree of coronary atherosclerosis with age in men. Circ 1950;1:645. Crossref

15. Berenson GS, Srinivasan SR, Newman WP.Association between multiple cardiovascular risk factors and atherosclerosis in children and young adults. The N Eng J Med 1998;338:1650-65. Crossref

16. Auerbach O, Hammond EC, Garfinkel L. Smoking in relation to atherosclerosis of the coronary arteries. N Engl J Med. 1965;273:7759. Crossref

17. Porett PM, Roses RE, Frederick JR editors. The Surgical Review: An Integrated Basic and Clinical Science Study Guide. 2nd ed.Philadelphia;2009.347pp.

18. Klatsky Al, Friedman GD, Siegelaub MS, Gerard MJ. Alcohol consumption and blood pressure.Kaiser-Permanente Multiphasic Health Examination Data. N Engl J Med 1977;296:1194-200. Crossref

19. Tauqir Y. Goraya, Cynthia L. Leibson, Pasquale J. Palunbo. Coronary atherosclerosis in diabetes mellitus. J Am Coll Cardiol. 2002;40:94653. Crossref

20. Bahl VK, Prabhakaran D, Karthikeyan G. Indian Heart Journal. 2001;53:707-13. PMCID: PMC3336855.

21. Enas EA, Senthilkumar A. Coronary artery disease in Asian Indians: an update and review [online] Internet J Cardiol. 2001:1. Accessed 15 Feb 2005. Crossref 